\title{
Double Arcus Senilis
}

\author{
Sana Nadeem ${ }^{1}$ \\ ${ }^{1}$ Department of Ophthalmology, Foundation University Medical College/Fauji Foundation Hospital, Rawalpindi
}

\begin{abstract}
Arcus senilis is the commonest of the corneal degenerations and presents as a whitish or yellowish band in the corneal periphery, associated with the deposition of lipoproteins in the corneal stroma. It is separated from the limbus by a clear zone. It is most commonly associated with aging. Other associations are hyperlipidemia, particularly in men less than 50 years (arcus juvenilis). However, a double arcus is very rare and only few case reports are found in literature. I present a case of 68-year-old man with diabetes mellitus and 35 pack years of smoking who presented to us in the outpatient Department. He had double corneal arcus in both eyes. There was a distinct clear line between the two arci. The case is presented with a brief discussion on the traditional risk factors, possible pathogenesis and literature review.
\end{abstract}

Key Words: Arcus senilis, Gerontoxon, Arcus Juvenilis.

How to Cite this Article: Nadeem S. Double Arcus Senilis. Pak J Ophthalmol. 2020; 36 (4): 448-450.

Doi: https://doi.org/10.36351/pjo.v36i4.884

\section{INTRODUCTION}

Corneal arcus (gerontoxon or arcus lipoides) is the stromal deposition of a greyish white or yellow band of opacification about $1 \mathrm{~mm}$ wide in the peripheral cornea. The clear zone between it and the limbus, about $0.3 \mathrm{~mm}$ wide, is called the lucid interval of Vogt. Its central border is diffuse, and the peripheral border is sharper. It is circumferential, beginning superiorly and inferiorly, gradually spreading to the nasal and temporal regions, and is most dense superiorly. The arcus is almost always a bilateral condition, but may be asymmetric in carotid vascular disease, being less on the involved side, and is increased in eyes with chronic hypotony. In males, it occurs increasingly from the age of 40 years; is seen in $90 \%$ of normal men between $70-80$ years of age, and in almost all above 80 years. In females, it is seen similarly, but

Correspondence: Sana Nadeem

Department of Ophthalmology, Foundation University Medical College/Fauji Foundation Hospital, Rawalpindi Email: sana.nadeem018@gmail.com

Received: September 12, 2019

Accepted: March 2, 2020 with a 10 year delay. ${ }^{1}$ Double arcus senilis is a very rare entity and we are submitting this report from Pakistan.

\section{CASE PRESENTATION}

A 68-year-old man with a history of diabetes mellitus for the past 10 years, hypertensive and a smoker of filtered cigarettes of 35 pack years, presented to our Eye OPD of Fauji Foundation Hospital, Rawalpindi. It is a tertiary care, teaching hospital affiliated with the Foundation University Medical College. The patient had mild blurring of vision. Best corrected vision OD was $6 / 6$ and 6/12 OS. On examination, he had bilateral double arcus senilis, with a circular, clear zone between the two. There was a clear area between the limbus and arcus peripherally as well [Figures 1,2]. The outer arcus was separated from the limbus by a clear zone. The inner arcus was complete but thinner as compared to the outer arcus. The arci involved almost full stromal thickness temporally and nasally, but $2 / 3^{\text {rds }}$ stromal thickness superiorly and inferiorly. [Figure 3].

He had bilateral mild nuclear sclerosis and intraocular pressures were $29 \mathrm{~mm} \mathrm{Hg}$ OD and $33 \mathrm{~mm}$ Hg OS with Goldmann applanation tonometry. He had 
open angles on gonioscopy by Shafer classification (grade IV) bilaterally; and central corneal thickness (CCT) was $530 \mu \mathrm{m}$ OD and $529 \mu \mathrm{m}$ OS. Cup disc ratios (CDRs) of $0.8 \mathrm{OD}$ and $0.6 \mathrm{OS}$ were observed. He was started on Cosopt ${ }^{\circledR}$ eye drops (dorzolamidetimolol) twice a day, and perimetry and optical coherence tomography (OCT) of the optic nerve head and retinal nerve fibre layer, was ordered immediately, which confirmed the diagnosis of primary open angle glaucoma.

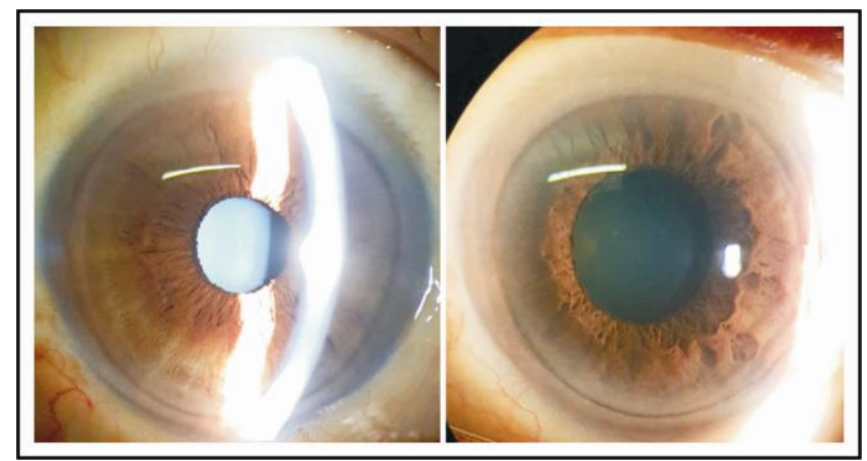

Fig. 1: A. Double arcus senilis in the right eye, with a clear zone separating the two arci. B. Scleral scatter enhancing the arcus.

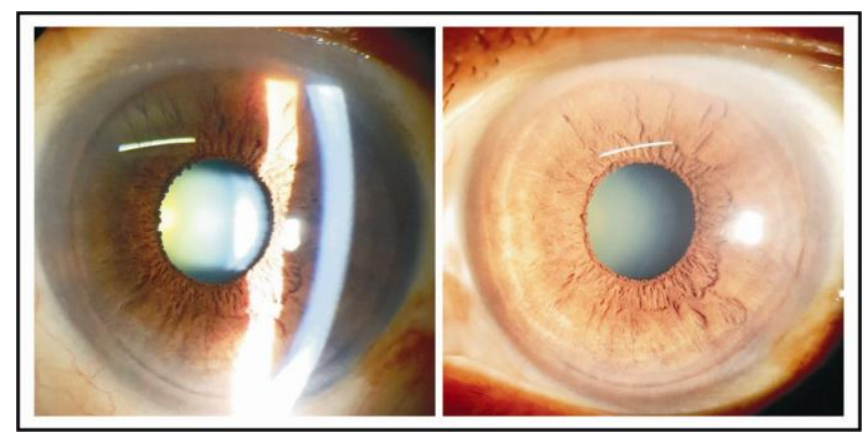

Fig. 2: A. Double Arcus in the Left Eye (Focal Illumination). B. Diffuse Illumination Showing Two Complete Rings.

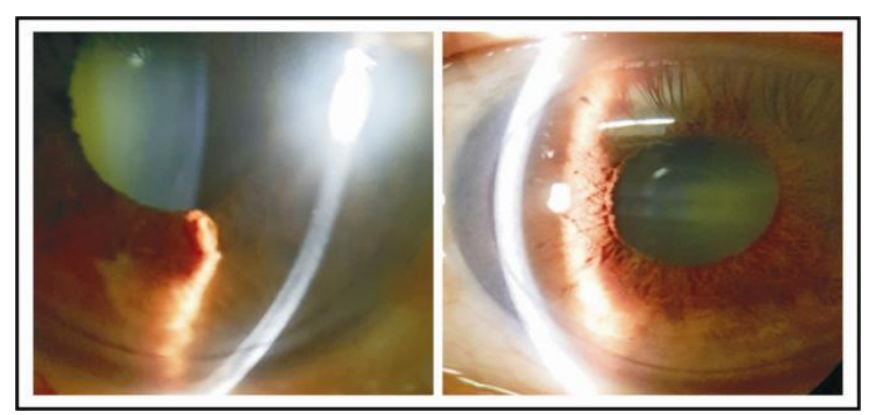

Fig. 3: A. Inferior corneal optical section shows about $2 / 3^{\text {rds }}$ of stromal thickness involvement by the arcus. B. Peripheral corneal optical section showing full thickness stromal involvement by both arci.
Routine investigations were ordered, complete blood picture (CBC) which was normal, random blood sugar (RBS) was uncontrolled $(20.8 \mathrm{mmol} / \mathrm{L})$, and so was $\mathrm{HbA1c}$ at $10.3 \%$. Serum cholesterol $(4.8 \mathrm{mmol} / \mathrm{L})$ and HDL $(1.08 \mathrm{mmol} / \mathrm{L})$ were normal, and serum triglycerides $(4.3 \mathrm{mmol} / \mathrm{L})$ and serum $\mathrm{LDL}$ (3.6 $\mathrm{mmol} / \mathrm{L}$ ) were high. LFTs, RFTs and urine RE were normal. He was referred to a medical specialist for diabetes and hypertension control and altered lipid profile. Currently, his medical condition is well controlled on oral therapy. His double corneal arcus is stable at the moment and intraocular pressures are well controlled on Cosopt BD.

\section{DISCUSSION}

Arcus senilis is the most common corneal degenerations, and although visually innocuous, needs discussion, especially if double arci are seen in any individual. The deposits of arcus senilis are made up of cholesterol, phospholipids, and triglycerides. ${ }^{2}$ Lipid material leaks from the limbal capillaries from the deep scleral vascular plexus, and is deposited in the corneal periphery, but its central flow is halted by a functional barrier in the cornea, which keeps the larger molecules from being deposited centrally. ${ }^{1,3}$

Arcus senilis is most commonly associated with aging. Other associations are hyperlipidemias, particularly in men less than 50 years (arcus juvenilis), who also have an increased risk of cardiovascular disease. Male gender, smoking, and hypertension are other associated risk factors. ${ }^{4}$ In older patients, including diabetics; arcus senilis does not increase mortality. ${ }^{5}$

The mechanism of corneal arcus senilis formation involves increased permeability of the limbal blood vessels as a result of aging, thus allowing lipid molecules to diffuse into the stroma based on size and polarity; the lucid interval of Vogt being clear due to the lipid absorption into the circulation at the corneal periphery, as a result of closer proximity to the vascular arcade. ${ }^{3,6}$ These lipid particles are similar to those isolated from atherosclerotic plaques, but with the absence of foam cells. ${ }^{7}$

The pathogenesis of a double corneal arcus is still unclear; the inner arcus is thinner and smaller, as compared to the larger peripheral arcus, suggesting phenomenon similar to those seen in the formation of immunodiffusion rings ${ }^{3}$, and that the lipid molecules may diffuse differently according to size and polarity. 
Traditional risk factors for gerontoxon are old age, male gender, high body mass index, high total cholesterol, LDL, or triglycerides, and smoking. Additional risk factors described are systemic inflammatory markers like higher CRP (C-reactive protein), peripheral arterial disease, and chronic renal disease. $^{2,4,8,9}$

Double arcus senilis is very rare, with only few cases reported in literature. Literature review revealed the first two cases to be reported in 2002 by Agarwal ${ }^{5}$ in India, which were both elderly individuals with normal blood sugar and lipid profiles. The third case was reported in 2004 in Israel, in an old man with hypercholesterolemia. The fourth case was reported in 2007 by Vaikkakara ${ }^{9}$ in UK, in an elderly lady, who was eventually diagnosed with the milk alkali syndrome.

\section{Conflict of Interest}

Authors declared no conflict of interest.

\section{REFERENCES}

1. Lundström M, Barry P, Henry Y, Rosen P, Stenevi U. Evidence-based guidelines for cataract surgery: guidelines based on data in the European Registry of Quality Outcomes for Cataract and Refractive Surgery database. J Cat Refract Surg. 2012; 38 (6): 1086-1093.

2. Raj KM, Reddy PA, Kumar VC. Significance of corneal arcus. J Pharm Bioallied Sci. 2015; 7 (Suppl. 1): S14-S15. Doi: 10.4103/0975-7406.155765.
3. Hashemi H, Khabazkhoob M, Emamian MH, Shariati M, Fotouhi A. A population-based study of corneal arcus and its risk factors in Iran. Ophth Epidemiol. 2014; 21 (5): 339-344.

4. Moss SE, Klein R, Klein BE. Arcus senilis and mortality in a population with diabetes. Am J Ophthalmol. 2000; 129 (5): 676-678.

5. Agrawal S, Agrawal J, Agrawal TP. Double-ring corneal arcus. J Cataract Refract Surg. 2002; 28 (10): 1885-1886. Doi: 10.1016/s0886-3350(02)01672-3.

6. Gaynor PM, Zhang WY, Salehizadeh B, Pettiford B, Kruth HS. Cholesterol accumulation in human cornea: evidence that extracellular cholesteryl ester-rich lipid particles deposit independently of foam cells. J Lipid Res. 1996; 37 (9): 1849-1861.

7. Wu R, Wang JJ, Tai ES, Wong TY. Cardiovascular risk factors, inflammation, and corneal arcus: the Singapore Malay eye study. Am J Ophthalmol. 2010; 150 (4): 581-587.

8. Ang M, Wong W, Park J, Wu R, Lavanya R, Zheng $\mathbf{Y}$, et al. Corneal arcus is a sign of cardiovascular disease, even in low-risk persons. Am J Ophthalmol. 2011; 152 (5): 864-871.

9. Vaikkakara S, James RA, Pearce SH, Talks SJ. A second corneal arcus? Postgrad Med J. 2007; 83 (977): 153. Doi: 10.1136/pgmj.2007.057141.

\section{Author's Designation and Contribution}

Sana Nadeem; Assistant Professor: Concept, Design, Literature research, Manuscript preparation, Manuscript editing, Manuscript review. 